\title{
The effect of the Pandemic on European Narratives on Smart Cities and Surveillance
}

\author{
Mikołaj Biesaga ${ }^{1}$, Anna Domaradzka ${ }^{1}$, Magdalena \\ Roszczyńska-Kurasińska ${ }^{1}$, Szymon Talaga ${ }^{1}$, and Andrzej \\ Nowak ${ }^{2,3}$
}

\begin{abstract}
This paper presents the analysis of European smart city narratives and how they evolved under the pressure of the COVID-19 pandemic. We approach the smart city concept from the critical perspective of surveillance capitalism, as proposed by Zuboff (2019), to highlight the growing privacy concerns related to technological development. We have collected and analyzed 184 articles regarding smart city solutions, published on social media by five European journals between 2017 and 2021. We adopted both human and machine coding processes for qualitative and quantitative analysis of our data. As a result, we identified the main actors and four dominant narratives: regulation of $\mathrm{Al}$ and facial recognition, technological fight with the climate emergency, contact tracing apps, and the potential of 5G technology to boost the digitalization processes. Our analysis shows the growing number of positive narratives underlining the importance of technology in fighting the pandemic and mitigating the climate emergency. Although the discourse on surveillance is often accompanied by the consideration of the right to privacy, those types of concerns are central for only two topics out of the four we discovered. We found that the main rationale for the development of surveillance technologies relates to the competitiveness of the EU in the global technological rivalry, rather than increasing societal wellbeing or safeguarding the transparency of new policies.
\end{abstract}

\section{Keywords}

surveillance capitalism, smart cities, privacy

\footnotetext{
${ }^{1}$ Robert Zajonc Institute for Social Studies, University of Warsaw, Poland

${ }^{2}$ Faculty of Psychology, University of Warsaw, Poland

${ }^{3}$ Department of Psychology, Florida Atlantic University, USA

Corresponding author:

Mikołaj Biesaga, Robert Zajonc Institute for Social Studies, University of Warsaw, ul. Stawki 5/7, 00-183, Warsaw, Poland.

Email: m.biesaga@uw.edu.pl

Prepared using sagej.cls [Version: 2017/01/17 v1.20]
} 


\section{Funding}

The work of Mikołaj Biesaga, Szymon Talaga, and Andrzej Nowak was supported by the European Research Council (ERC) under the European Union's Horizon 2020 research and innovation program (grant agreement No. 952026). The work of Anna Domaradzka was supported by the Polish National Science Center under grant agreement no. 2018/30/E/HS6/00379.

\section{Introduction}

As a result of global pressure to make cities safer, more competitive, and climate neutral, both the European Union and the United Nations have led an effort to integrate the smart city model as part of a broader agenda for urban development (Albino et al. 2013; Swyngedouw et al. 2002). Among policymakers, the idea quickly spread, embodied by the new policy documents promoting the digitalization of public services. Cities, with their resources of know-how and funds, can easily develop, pilot, and scale up new ideas and concepts. That is why smart cities are at the center of the EC strategic vision for a modern, competitive, and climate-neutral economy described in the European Green Deal (2019). In Europe, European Commission (2020a) remains one of the most active actors promoting digital transformation and facilitating the smart city transition. In the beginning, the goal was to increase efficiency - smart cities were defined as those which can manage their resources, assets, and services more effectively for the benefit of local communities (Cohen 2015). Lately, the new goal of smart city policies became the formation of a climate-neutral, sustainable cities in which the use of resources is optimized, and production of waste limited. All of which is enabled by the introduction of digital surveillance technologies based on the system of sensors, cameras, drones, and diverse AI technologies monitoring processes occurring in the city.

The resulting implementation of smart city policies has brought new opportunities but also challenges and is often met with skepticism (Swyngedouw 2016). The critics point out that the urban smartness trend can easily lead to technocracy, making our cities more efficient and modern but less liveable, at least for those digitally excluded (Norris 2001; Dean 2017). For example, Melgaço and van Brakel (2021) compare investment in mass surveillance to a theatre in which politicians just play the role of crime fighters, while not being exactly interested in the effects of implemented solutions. Moreover, Jirón et al. (2021) suggest that sometimes smart city transitions take the form of creating the narrative of possible vaguely defined future benefits instead of promised quick fixes to the existing issues.

The danger is that we will continue to develop technologies without reflecting on the normative, behavioral, and ethical aspects of the new environment they create for individuals and communities, where efficiency is considered the top priority superior to human rights (such as the right to privacy or equal treatment). An important line of criticism is rooted in the concept of surveillance capitalism proposed by Zuboff (2019) who points out threats

Prepared using sagej.cls 
resulting from commodification and commercialization of data by big tech, which is further facilitated by smart city technologies (Kitchin et al. 2018; Zuboff 2019). Similarly, Wood (2015) argues that smart cities are by definition surveillance cities because their smartness is just a function of the data they constantly elicit from citizens. That is why privacy is often flagged as a critical concern (Löfgren and Webster 2020).

Despite those growing reservations, the last decade was marked by rapid growth in terms of smart cities implementations. In 2020, the COVID-19 pandemic created a powerful push toward the development of monitoring and tracking technologies, mainly implemented in dense urban environments. Temperature measuring points, compulsory apps using various sensors from personal devices, or contact tracing, turned out to be desirable solutions in the fight against the spread of the virus. The intensity of surveillance, however, made people wary of giving up more and more of their privacy and freedom for the sake of unregulated data collection. The European Commission (2020b) replied to those concerns by publishing interoperability guidelines for approved contact tracing applications. Still, the pandemic was one of the main impulses behind the increased implementation of smart solutions between 2020 and 2021 (Costa and Peixoto 2020). In this context we wanted to identify the dominant narratives in the European digital outlets, to see what main directions, arguments, and sentiments are present in the public discourse.

\section{The role of narratives in public policy}

Narratives are an important aspect of public policy because they do not only help people to build a shared understanding of reality, but they also reflect and shape attitudes and expectations of people (Collier 2016; Narlikar and Sottilotta 2021), which in the context of crisis can strongly influence citizens' response. Especially when tough choices must be made, narratives can be decisive in defining the choice architecture on the individual as well as policy level (Wydick 2015).

The meaning-making function of narratives (Boin et al. 2016) advanced by political leaders, also acquires a higher relevance in this context. Formulating a persuading narrative is often crucial for policy implementation, and a key source of legitimation (Jones et al. 2014). Some narratives inform and shape policies (Bevir and Rhodes 2006), providing persuasive public accounts of what is happening, why, and what can be done about it ('t Hart and Tindall 2009). As Drennan et al. (2014) point out, leaders - as primary storytellers - explain and simplify events during crises, to influence the behavior and performance of other actors. However, creating an attractive narrative can not be the sole goal of the smart city transitions. It must be paired with solving existing issues (Jirón et al. 2021; Valdez et al. 2018).

Our goal was to analyze the digital press narrative, to see if there was any significant change in how smart technologies were described over the last four years. We were also interested to see if the criticism toward smart city solutions and related surveillance technologies became more or less visible in the pandemic

Prepared using sagej.cls 
context. We start our analysis in 2017, which saw the delivery of most of the legislative proposals and policy initiatives announced in the EU Digital Single Market Strategy from 2015.

We focused on the public discourse on this subject, as reflected in five Europecentered journals, to identify main narratives as well as leading actors. We expected that in publications related to the wider critical discourse concerning smart cities we will observe a shift from the enthusiasm regarding amenities the technological solutions might offer, to a more critical approach toward the accelerated implementation of new surveillance technologies, like tracing apps or temperature measuring points, especially after the Cambridge Analytica (for a review see Cadwalladr and Graham-Harrison 2018) scandal and the discussion on surveillance capitalisms voiced by Zuboff (2019).

Our main focus was on surveillance in the context of European smart cities policies as well as specific technologies and implementations. We hypothesized that previous concerns about the loss of privacy and excessive surveillance by public authorities might lose significance in the crisis context (Kunzmann 2020). Secondly, we wanted to see whether the COVID-19 pandemic changed the narrative on the smart transition of European cities and consequently accelerated the implementation of policies and technologies. We expected that the intensity of the changes shifted the existing narrative towards threats that excessive data collection may pose for citizens. Thirdly, our goal was also methodological - we took this opportunity to compare the results of quantitative topic modeling with qualitative expert analysis of the same set of articles.

To summarize, our main research questions were: (1) What are the main narratives concerning smart technologies present in the studied media outlets? (2) Is surveillance and privacy an important part of narratives about smart city implementations? (3) Who are the main actors and what is the sentiment toward surveillance and smart city technologies in those narratives? (4) Has the pandemic changed the narratives on surveillance and smart city technologies? (5) Is machine coding of narratives accurate and as such a useful tool in discourse analysis?

\section{Materials and Methods}

We collected articles from five leading European online news outlets that publish articles in English on European affairs (predominantly they discuss issues concerning the European Union): POLITICO Europe (PE), Euronews English (EE), EUobserver (EUo), EURACTIV (EURA), and The Parliament Magazine $(\mathrm{PM})$. As the main journals' selection criterion, we used the popularity of their Facebook fan pages.

We started by collecting the content of all posts these journals created on Facebook from January 1st, 2017 to March 25th, 2021. For each post, we followed the link to the promoted article on the page of a given outlet and scraped its content. This way we assembled a database of 70,157 articles in total. Then, in order to analyze only articles discussing smart cities, technologies, and surveillance, we selected only those documents that contained at least one of the 
following pairs of keywords: 1) 'smart' and 'city', 2) 'city' and 'surveillance', 3) 'app' and 'surveillance', 4) 'AI' and 'surveillance'. This way we identified a subset of 625 articles. In the last step, we read the leads of all articles in the subset and selected 184 that specifically covered the issues of smart city technologies and surveillance.

\section{Quantitative analysis}

First, we investigated how frequently articles on smart cities, surveillance, and surveillance technologies were published over time. Then we performed topic modeling using Latent Dirichlet Allocation (Blei et al. 2003). We used a fullfeatured, industrial-strength implementation provided by the Gensim library for Python programming language (Rehurek and Sojka 2010). It allowed for separating groups of articles (topics) that are characterized by similar word distributions.

The LDA method assumes that the observed patterns in the document can be explained by the fact that each document is a mixture of a small number of topics and each topic is associated with a particular probability distribution over words. Therefore, articles related to the same topics use similar words.

Although the topics were discovered based on the observed distributions of words and therefore results are purely data-driven, the crucial decision on the number of topics to look for has to be made by the researcher. We based the selection of the correct number of topics (groups into which fall the articles) on a coherence measure that considers both the similarity of the articles within the topics and the variety of the topics (Röder et al. 2015). This required producing several models for different numbers of clusters (topics) and comparing them on a coherence measure. We tested the vector of possible solutions from 3 to 10 topics and used an asymmetric confirmation measure - UMass coherence index proposed by Mimno et al. (2011) to chose the number of topics that would best fit the data.

For each topic, we identified actors using a full-featured, state-of-the-art Natural Language Processing library for Python - SpaCy (Honnibal et al. 2018). It allowed for Named Entity Recognition (NER) tagging. Based on the results, we were able to identify the main actors in the whole corpus and track their appearance over time in each of the topics. We calculated a saturation index showing the frequency in which individual actors appear in articles from a given topic. The saturation index ranges from 0 (the actor is not mentioned in any of the articles consisting of the topic) to 1 (all of the articles in the topic mention the actor). Finally, we computed the sentiment of each of the topics. We built our metric on top of the popular sentiment model for English - VADER (Hutto and Gilbert 2014). To be able to compare the texts of different lengths we defined a simple metric that weighs the compound score, a sum of the valence scores of each word in the lexicon, by the actual rate of non-neutral sentiment:

$$
\text { sentiment }=\text { compound } \times(1-\text { neutral })
$$

Prepared using sagej.cls 


\section{Qualitative analysis}

As the final step of our analysis, we performed a qualitative analysis of the corpus of all 184 articles. Three researchers read and coded one-third of the articles in MAXQDA software, developing data-driven coding trees. The trees were compared and merged into the new coding tree, focusing on the main themes and recurring topics. All codes as well as controversial cases were discussed and reviewed by all, to make sure researchers share the same definitions of codes. The main areas of analysis concerned the identification of actors (including cities, countries, institutions, companies, and NGOs), identification of main technologies, and extraction of threats and opportunities that emerging technology brings about.

\section{Results}

\section{Surveillance and privacy in narratives on smart cities}

We started our analysis by examining the co-occurrence of keywords like 'smart' and 'city', 'surveillance' and 'privacy' over time. The main aim here was to investigate the effect of the COVID-19 pandemic on narratives concerning smart cities, surveillance, and technologies like AI or contact tracing apps. We found out that the topic of smart city, although regularly mentioned, was not very popular in the studied period (2017-2021). On average, there was one article published on the subject per month. The link between smart cities and surveillance was not uniform in time. At the beginning of the studied period, the articles on smart cities did not reflect on surveillance or privacy at all. These issues entered the discussion on cities just in the second quarter of 2018, the same time when the malpractice of Cambridge Analytica was revealed. The articles on technologies like smartphone apps and AI started to touch the topic of surveillance and privacy at a similar time.

Figure 1 illustrates that the COVID-19 pandemic had an especially big effect on the frequency of occurrence of articles on the topic of apps and surveillance. There was a clear spike at the beginning of the pandemic in the volume of articles that contained pairs of words like 'privacy app' and 'surveillance app'.

The popularity of discourse on surveillance and privacy in the context of artificial intelligence (AI) was also affected by the onset of the pandemic, but in the opposite direction - the pandemic narrative seemingly stifled the topic for a few months. The peak of popularity of AI-related topics in which surveillance or privacy was mentioned fell just a month before the pandemic outbreak (Figure 1 ). The pandemic had the same chilling effect on the occurrence of articles about smart cities - since March 2020, in some months the topic was not mentioned even once in pan-European news outlets. During the pandemic, the city was discussed in the context of surveillance, but less in the context of privacy.

\section{Main actors of the narratives}

Here we report only on the frequency with which the specific cities, countries, and institutions are mentioned in the selected articles, while the context in which 

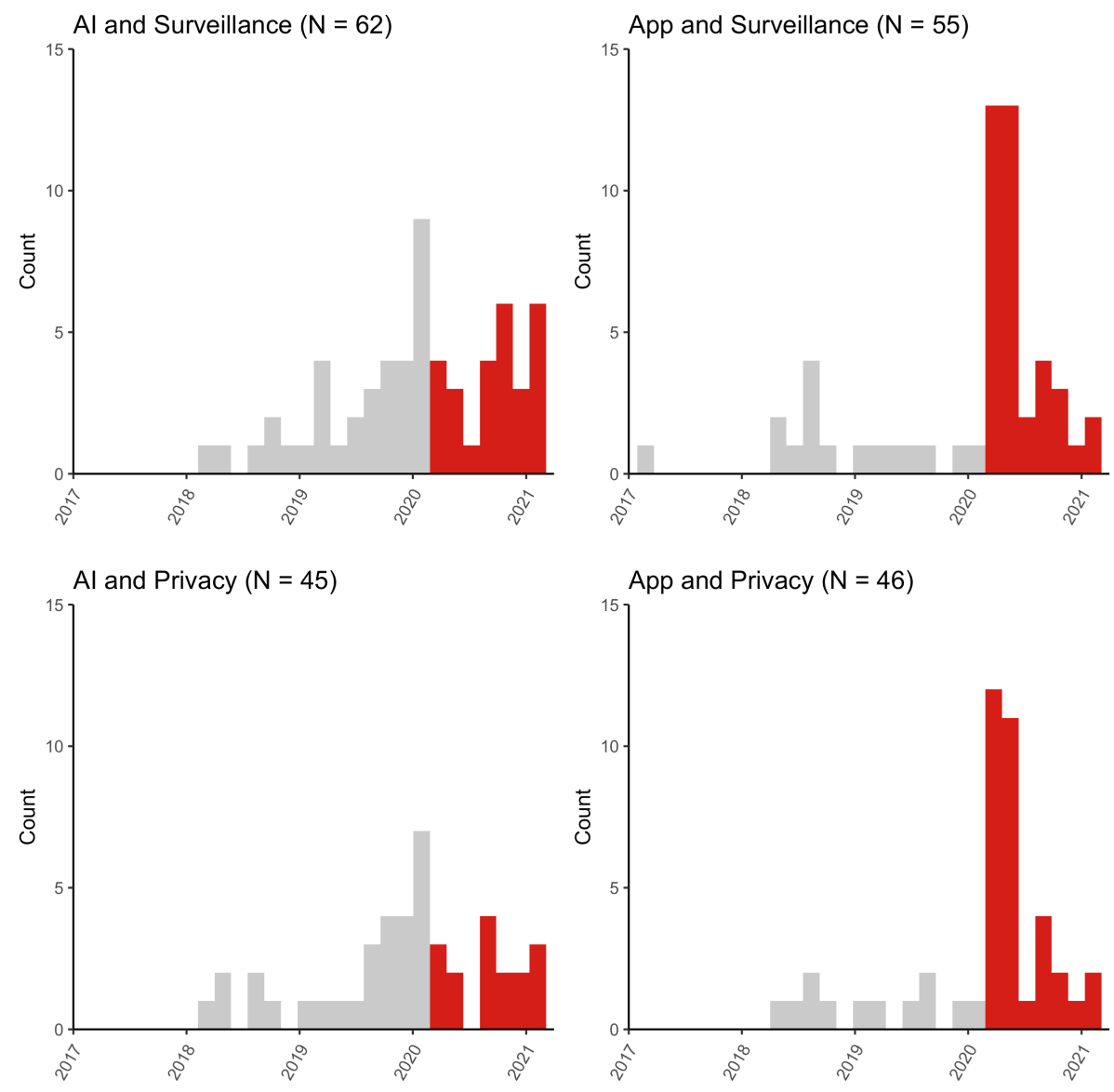

Figure 1. Privacy and Surveillance in articles about apps and AI. Red indicates articles published after the onset of the pandemic.

specific actors appear will be discussed later. There were not many European cities that were mentioned by their names. The most popular were: Brussels (96), London (55), Stockholm (54), Berlin (46), and Paris (41). Other, non-European cities appearing relatively often were Beijing, Hong Kong, Washington, and Moscow. In terms of regions, Europe was the most often cited geographical location (514), which comes as no surprise considering the choice of media outlets. In terms of countries present in the analyzed articles, the United States (272), together with the United Kingdom (197) and China (192) were the most often mentioned countries from outside of the EU. Germany (152) and France (121) were referred the most among the member states. Other frequently discussed country-actors included Poland (58), Italy (54), Sweden (39), Spain (34), and Finland (34).

Prepared using sagej.cls 
Tech companies were mentioned quite often, while most of them represented the US Silicon Valley companies (Google - 178, Apple - 123, and Facebook 196), there were also numerous mentions of Chinese companies including Huawei (127), ByteDance (43) - Chinese tech giant and owner of TikTok, Alibaba (10) China's dominant e-commerce and cloud company, Nuctech (8) - a state-owned manufacturer of X-ray machines, scanners, and explosive detection systems, DJI (4) - a private drone-manufacturing company based in Shenzhen. Telephone companies emerged as a specific cluster in the discussion, with Vodafone (20) and Ericsson (5) being most frequent.

European Union institutions were referred to in various manners: as EU (805), European Commission (139), or Brussels (96). Taken together this was the most important group of actors present in the analyzed corpus. Police forces from different countries and cities were often mentioned in the context of threats related to technological implementations (217). The watchdog organizations, although not as visible as public and private organizations, also appeared in the narratives. Privacy Shield (18), Amnesty International (17), and Human Rights Watch (5) were the three most often mentioned organizations.

\section{Main technologies}

In 184 analyzed articles, we counted 679 mentions of AI (or Artificial Intelligence), 388 mentions of $5 \mathrm{G}$ network, 327 mentions of Face Recognition technologies (FR), and 103 mentions of tracing (or tracking) apps. Other technologies included self-driving cars (or driverless cars) (113), drones (51), robots (46), Bluetooth (27), and other forms of automation (10).

\section{Main topics on smart cities and surveillance}

The corpus of the articles was divided automatically via Latent Dirichlet Allocation into seven main topics, out of which three were excluded. Two of those were composed of only 4-5 articles, too small to perform a reliable quantitative analysis. The third excluded group was composed of 14 articles, most of which were Digital Briefs published by EURACTIV. While Digital Briefs are composed of very short texts, including highlights about technology and digitalization, it was impossible to extract any main narrative from them.

In the end, four main topics of narratives were defined: AI and FR (Topic 1), innovations that help to overcome the climate emergency (Topic 2), tracking apps (Topic 3), and 5G technology (Topic 4). Below we describe each topic in detail, summarizing results in Table 1.

Topic $1-A l$ and Facial recognition The first and most prominent topic was composed of 82 articles that dealt with Artificial Intelligence (AI), facial recognition (FR), and their regulation (Figure 2). The geopolitical focus of this topic lies with the EU, China, and the USA (Table 1). Police of different countries is the main actor of many articles here. Companies play a secondary role in this topic. The narrative on AI and FR quite often refers to privacy and surveillance concerns. Privacy as well as the General Data Protection Regulation introduced by the European Commission are mentioned regularly.

Prepared using sagej.cls 

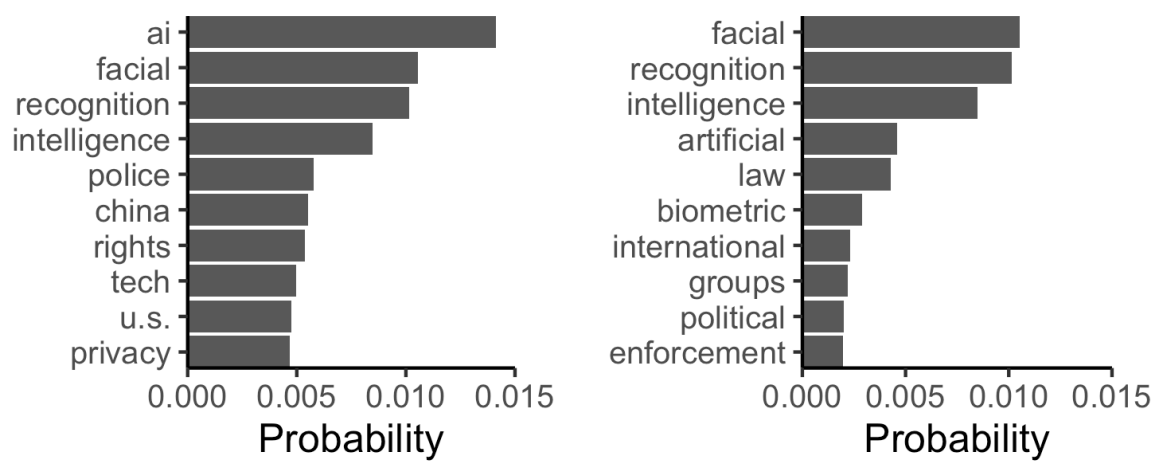

Figure 2. Most probable words in Topic 1 (left panel) and the probability of words that are unique for Topic 1 (right panel).

The algorithmic analysis of sentiment shows that although the majority of articles is rather positive, one-quarter of them reveals a negative attitude to either the AI and FR technology or their regulation.

Qualitative analysis showed that FR systems were often mentioned in the context of police efforts to introduce new safety measures in the public space as well as during protests or other mass events. FR requires creating the database of faces and their IDs, and that is why it often involves the use of some form of Artificial Intelligence algorithms to compute and compare large bodies of data. While automated processing of data is by design not objective, the articles concerning FR often pointed out the examples of AI bias and the threat of discrimination of specific groups - women, racial and ethnic minorities, and people with disabilities. The articles on Artificial Intelligence, and Facial Recognition raised concerns on two main levels: AI bias and FR threat to privacy.

Topic 2 - smart technologies to fight the climate emergency The second topic was composed of 38 articles that represented the discussion of Europe's fight against the climate emergency with innovation and smart technologies (Figure 3). Qualitative analysis pointed out the connection of smart cities with creativity, waste management, energy, heating, and transportation. In most of the articles, the focus was on the EU. Only individual mentions of other countries (like China, the USA, Sweden, and Germany), as well as technological companies (like Apple, Google, and Nokia) could be found. This type of narration was characteristic for the pre-pandemic period and was definitely positive. Surveillance and privacy were not a cornerstone of this topic.

The qualitative analysis of articles in this topic showed that the issue of dealing with the side products of scaling up technological development raises as a pressing challenge. According to some articles, recycling smartphones, cables, computers, microchips, and so on is an important part of building a sustainable

Prepared using sagej.cls 

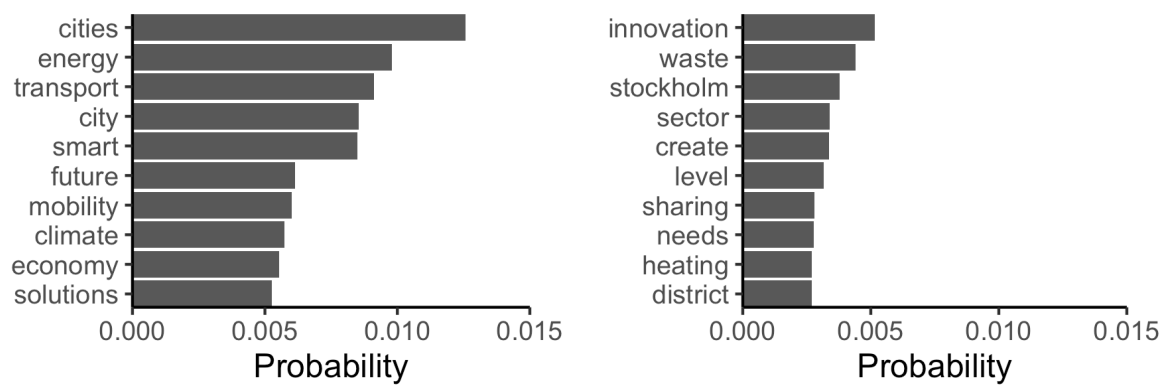

Figure 3. Most probable words in Topic 2 (left panel) and the probability of words that are unique for Topic 2 (right panel).

smart future for European cities. Both because this type of waste is dangerous, and because the rare metals are running out and the components are going to be more difficult to produce in the future.

Another important environmental issue mentioned in the articles was the heating effect of server farms and other ICT infrastructure required for the implementation of smart cities innovations. Some circular, closed-loop, and nature-based solutions were mentioned as possible solutions to this challenge. Third, a prominent subtopic described the process of developing smart solutions for cities as the necessary response to the climate emergency.

Topic 3 - technology to fight the COVID-19 pandemic The third group of articles was composed of 28 articles that addressed the topic of contact tracing apps as a tool for fighting the spread of COVID-19 (Figure 4). The apps, developed in many countries simultaneously, were supposed to help manage testing and quarantine processes and consequently reduce the spread of coronavirus. This narration surfaced in 2020 and lasted till the end of the examined period. The most discussed regions/countries in this context were the EU, Germany, France, UK, and Poland, with China playing a peripheral role. Two international technological companies were important actors here - Google and Apple. Although the problem of privacy and surveillance was discussed greatly within this topic, most of the articles seem to have positive sentiment, there were only some articles that expressed negative sentiment.

Qualitative analysis showed that tracking apps were often described as 'necessary evil' and part of national efforts to curb the spread of the virus. Articles often cited criticism concerning the amount of private data that is being collected, as well as doubts towards the potential collaboration of governments with tech giants like Apple or Google in creating tracing applications.

Topic 4 - for digitalization of Europe The fourth topic was composed of 13 articles that focused on the potential of $5 \mathrm{G}$ technology to boost the digitalization processes in Europe (Figure 5). The implementation of 5G technology in this narration is presented as a cornerstone of the development of smart cities that 

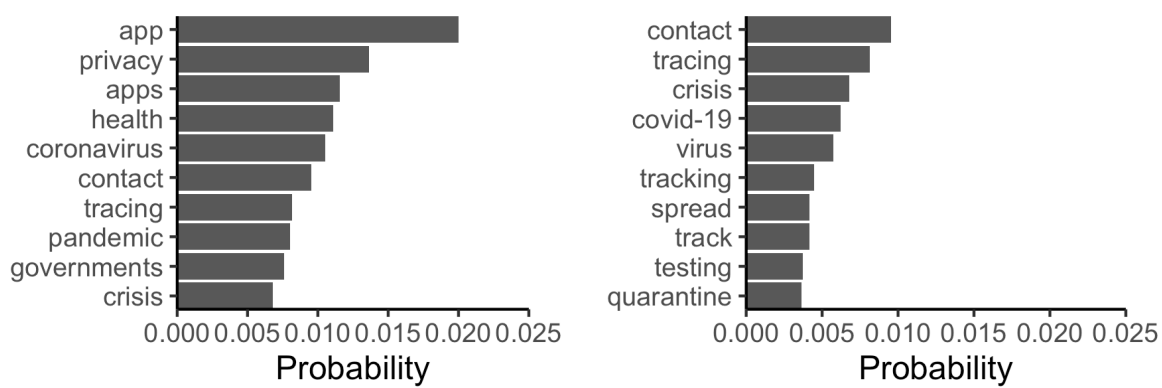

Figure 4. Most probable words in Topic 3 (left panel) and the probability of words that are unique for Topic 3 (right panel).

utilize countless smart devices. The high occurrence of words like health, body, waves, and radiation indicated that the discourse on the development of $5 \mathrm{G}$ is accompanied by health concerns. The narrative about $5 \mathrm{G}$ is relatively new - it started in 2019 - and it refers mainly EU and the European Commission. The companies that are mentioned in this context were Amazon, Google, Facebook, and Huawei. The issues of surveillance and privacy almost did not occur, the sentiment of the narration was positive.
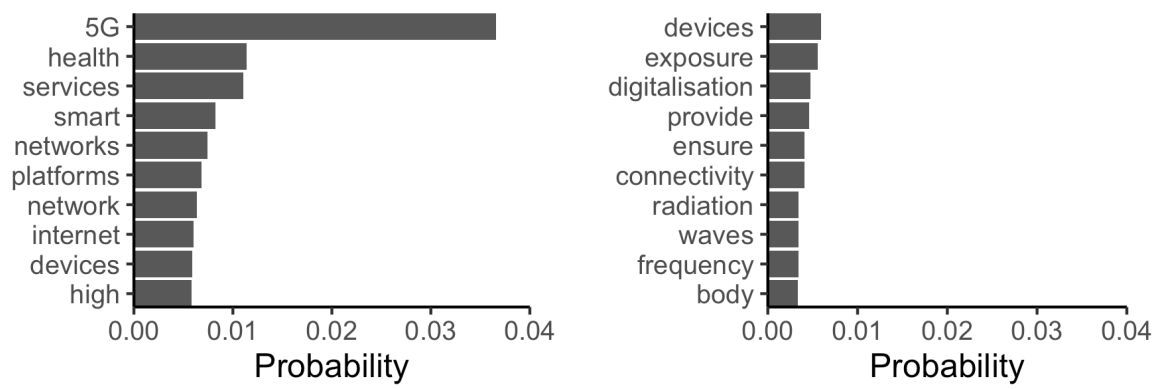

Figure 5. Most probable words in Topic 4 (left panel) and the probability of words that are unique for Topic 4 (right panel).

The qualitative analysis of articles revealed that the due to network's greater bandwidth, offering higher download speeds, it is expected that the networks will make possible the new applications of the internet of things (IoT) and other forms of digital services. Articles mentioning this technology usually warned against the growing dominance of non-European suppliers, mainly Huawei that was meant to provide 5G infrastructure for the European Union digital ecosystem. Most articles discussed this Chinese $5 \mathrm{G}$ company in terms of potential threats to European data security. Often the narrative touched upon 
the risk of $5 \mathrm{G}$ networks increasing the vulnerability of core functions of public data systems to potential errors and cyber-attacks.

Interestingly, we could observe the change of the $5 \mathrm{G}$ narrative over time, with more criticism at the beginning of implementation and many mentions of Huawei dominance as a threat to EU security in 2019 articles. However, with time, the tone of the narrative changed and focused on the issue of global competitiveness and how developing European 5G solutions is the only way for the EU to remain a relevant actor on the global digital market, without risking Chinese technological monopoly within the Union as well as globally.

Table 1. Summary of main topics (saturation index in parentheses).

\begin{tabular}{|c|c|c|c|c|}
\hline Topic & Actors & $\begin{array}{c}\text { Time frame and } \\
\text { sentiment }\end{array}$ & $\begin{array}{c}\text { Surveillance and } \\
\text { privacy }\end{array}$ & $\begin{array}{c}\text { Qualitative analysis } \\
\text { summary }\end{array}$ \\
\hline $\begin{array}{l}\text { Topic } 1 . \\
\text { AI and } \\
\text { FR }\end{array}$ & 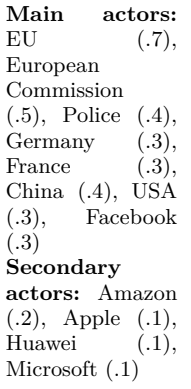 & $\begin{array}{l}\text { 2017-2021 } \\
\text { Polarised sentiment } \\
-\quad \text { one quarter } \\
\text { of articles elicit } \\
\text { negative sentiment }\end{array}$ & $\begin{array}{l}\text { Surveillance }(.8) \\
\text { Privacy }(.6)\end{array}$ & $\begin{array}{l}\text { FR is a threat to privacy. AI } \\
\text { bias is a threat to equality and } \\
\text { justice. FR systems do not seem } \\
\text { to be as effective in finding } \\
\text { criminals as the police claims. }\end{array}$ \\
\hline $\begin{array}{l}\text { Topic } \\
2 . \quad \text { Smart } \\
\text { technologies } \\
\text { for climate }\end{array}$ & $\begin{array}{l}\text { Main actors: } \\
\text { EU (.7), } \\
\text { European } \\
\text { Commission } \\
(.4) \\
\text { Secondary } \\
\text { actors: China } \\
(.2), \text { Germany } \\
(.1), \text { Sweden }(.1) \text {, } \\
\text { and USA (.1) }\end{array}$ & $\begin{array}{l}\qquad 2017-2019 \\
\text { Positive } \\
\text { sentiment }\end{array}$ & $\begin{array}{l}\text { Surveillance }(.1) \\
\text { Privacy }(.1)\end{array}$ & $\begin{array}{l}\text { Smart technologies as a way } \\
\text { forward in building climate } \\
\text { neutrality. Chance for closing } \\
\text { gaps. The threats related to } \\
\text { recycling of technological waste } \\
\text { and the heating effect of server } \\
\text { farms. }\end{array}$ \\
\hline $\begin{array}{l}\text { Topic } \\
\text { 3. Anti- } \\
\text { pandemic } \\
\text { technologies }\end{array}$ & $\begin{array}{l}\text { Main actors: } \\
\text { EU (.5), } \\
\text { European } \\
\text { Commission } \\
(.4), \quad \text { Germany } \\
(.5), \text { France }(.5) \text {, } \\
\text { Poland }(.3) \text {, UK } \\
(.3), \text { Google }(.4), \\
\text { Apple }(.3) \\
\text { Secondary } \\
\text { actors: China } \\
(.2) \text { and } \\
\text { Facebook }(.1)\end{array}$ & $\begin{array}{l}\qquad \text { 2020-2021 } \\
\begin{array}{l}\text { Ambiguous } \\
\text { sentiment, } \\
\text { predominance } \\
\text { positive }\end{array}\end{array}$ & $\begin{array}{l}\text { Surveillance }(.7) \\
\text { Privacy }(.8)\end{array}$ & $\begin{array}{l}\text { Technologies help Europe } \\
\text { recover from the crippling } \\
\text { effects of the COVID-19 crisis. } \\
\text { Tracking apps as 'necessary } \\
\text { evil'. A close collaboration } \\
\text { between public sector and } \\
\text { private corporations is a } \\
\text { potential threat to privacy. }\end{array}$ \\
\hline $\begin{array}{l}\text { Topic } \\
4 . \quad 5 \mathrm{G} \\
\text { network }\end{array}$ & $\begin{array}{l}\text { Main actors: } \\
\text { EU (.7) and } \\
\text { European } \\
\text { Commission } \\
(.5) \\
\text { Secondary } \\
\text { actors: Amazon } \\
(.2) \text {, Facebook } \\
(.2) \text {, Google }(.1) \text {, } \\
\text { Huawei }(.1)\end{array}$ & $\begin{array}{c}\text { 2019-2021 } \\
\text { Positive sentiment }\end{array}$ & $\begin{array}{l}\text { Surveillance }(.2) \\
\text { Privacy }(.2)\end{array}$ & $\begin{array}{l}5 \mathrm{G} \text { as a tool for developing } \\
\text { the EU digital market. } \\
\text { Slow implementation of EU } \\
5 \mathrm{G} \text { infrastructure risks the } \\
\text { dominance of non-European } \\
\text { suppliers. Open debate on 5G's } \\
\text { benefits and threats is needed } \\
\text { in the EU. }\end{array}$ \\
\hline
\end{tabular}




\section{The effects of the COVID-19 pandemic on narratives - qualitative analysis}

Before the pandemic, we distinguish three main narratives focused on a) privacy and data security, b) economic competitiveness of the EU, and c) measures mitigating the climate emergency in EU cities. The issue of climate change was very much pronounced as both the reason for implementing new technologies as well as the higher purpose of smart city technologies. Achieving carbon neutrality and mitigating the climate crisis set the ground for a positive evaluation of new smart city technologies within the studied narrative.

Since the start of the COVID-19 pandemic, an increase of articles focused on tracing apps and surveillance technologies could be observed. We could also distinguish an additional topic that has not emerged in the first step of quantitative topic analysis:

Pandemic as a fast-tracking factor in technological development One of the leitmotifs in the discussion concerning the technological countermeasures to the pandemic was the widespread privacy concern and fear that once the surveillance technology is implemented it will not be switched off after the health threat is over:

The response of EU countries to the coronavirus outbreak has prompted unprecedented levels of surveillance, data exploitation, and misinformation. Data collection can be essential to understand and respond to the Covid-19 emergency, but creating such digital surveillance risks failure and adverse side-effects. (EUobserver, 202004-12)

Privacy concerns were related to the amount of private data (including sensitive data on health, contact lists, etc.) that contact tracing apps are collecting and fears that the data will not be safe and may be used for commercial or political reasons. The speed of introducing new technologies created understandable doubts about their security and resistance to theft or other forms of abuse:

Big Tech has become a global punching bag because of fears that Silicon Valley has too much control over our daily lives. But in their legitimate efforts to keep people safe, officials across the European Union, United States and elsewhere are quickly falling into the same trap - creating a government surveillance network on the fly, with little oversight and almost no clarity about when it will be shut down.

(POLITICO Europe, 2020-04-19)

Those doubts bring the trade-off between health and privacy to light. The need to quickly implement countermeasures to stop the spread of the virus meant that many governments decided to suspend the citizens' right to privacy. The urgency of the matter meant that no wider public debate on the topic was possible. Therefore, some of the articles underlined the need for public scrutiny over those new apps and different ICT solutions:

Prepared using sagej.cls 
This opens up a key question, on how to toe the line between privacy and the need to use data in order to slow down the pandemic. (...) because of the speed at which these are being implemented, they are avoiding public and political scrutiny (...) In these unprecedented times, there has been a monumental shift in personal liberties, and there is undoubtedly a trade-off to be had between privacy and the need to curtail the spread of the pandemic, but what measures are appropriate, and will they have a long-lasting societal effect? (Euronews English, 2020-03-31)

In the case of some articles, authors and cited experts pointed out that the governments (sometimes hand in hand with technological companies) are using the pandemic as an excuse to fast-track the surveillance technologies. For governments, those technologies are useful tools for amassing power, stifling protests, or weakening the opposition. For companies, they can be easily turned into profits and sold to the highest bidder.

Technology can be used in preserving very much the privacy of people and it will be extremely useful for us in the face of the COVID-19 crisis. But if, by any chance, mass surveillance develops in Europe, it will not have been for the coronavirus. The coronavirus will have been an excuse for this to happen. (Euronews English, 2020-03-31)

As officials around the world struggled to contain the COVID-19 pandemic, they were increasingly turning to the surveillance methods already used in some Asian countries to track people's movements and contacts. That has raised questions about privacy and timeframe of urgency measures - in other words when the tracking will be switched off. Some articles pointed out the need to think about the after-COVID reality and make sure that surveillance does not become a 'new normal', but a temporary fix. Otherwise, some authors warned, European countries and cities risk turning into surveillance zones'

We need an independent state figure that's not the government who can guarantee this data will eventually be deleted, (...) We need to ask the questions: When will this stop, and who will get to decide? (POLITICO Europe, 2020-04-02)

A solution to this threat may be to give control over harvested data to civil society actors rather than governments or private firms. However, it seems that the European Commission can only create guidelines and recommendations, while the nation-states and municipalities are experimenting with different solutions and regulations concerning data protection.

Technology threats - qualitative analysis The quantitative analysis allowed us to distinguish technology threats that repeatedly appeared in the articles but did not show up in the quantitative analysis.

The narrative about technological threat usually serves as a negative benchmark or 'dark scenario' used to illustrate the possible dangers of abusing

Prepared using sagej.cls 
technological developments to tighten control over citizens and strengthen nondemocratic regimes. China and Russia are often mentioned in this context, followed by the USA, Hungary, or Serbia.

The emerging technologies can, for example, be abused by authoritarian regimes to set up a ubiquitous surveillance apparatus. Most prominently, China has been using cutting-edge AI to build up a high-tech surveillance system and crack down on political dissent, according to media reports - and other countries around the world, including European nations such as Serbia, have struck deals with Chinese companies to introduce their own systems aimed at monitoring individuals. (POLITICO Europe, 2019-06-24)

Another narrative, usually paired with the previous one concerns authoritarian regimes. It focuses on the worrying developments within the European Union, concerning the growing power supplied to governments by big data and surveillance technologies. This often specifically relates to the use of cameras and drones by the police and boarding patrol, describing tools like face recognition, surveillance drones, or contact tracing. The main concern here is that even if implemented in good faith, the solutions will allow the abuse of power in the longer run. Distrust towards the government, in countries such as Germany or the UK, is the main leitmotif here. New developments concerning the pandemics are also mentioned in this context, as factors fasttracking the development of surveillance that may stay in place even after the state of emergency.

People are growing increasingly sceptical about how Google, Amazon and Facebook collect reams of our personal data, often in opaque ways that are hard to decipher. So why shouldn't governments come under the same scrutiny? Governments that have a track record of failing to keep such digital information safe, lack Big Tech's technical expertise and will, for the most part, be beholden to themselves about when to call off their digital land grab. (POLITICO Europe, 2020-04-19)

In tackling the pandemic, we must avoid Europe sleepwalking into a permanent expanded surveillance state. (EUobserver, 2020-04-24)

We found one more recurring narrative concerning the possible societal dangers of implementing AI in different policy areas. Often, the discussed form of $\mathrm{AI}$ is the one relating to face recognition technology. Articles often point out that AI proves to incorporate human bias and even strengthen it, which is visible in its reactions and evaluation procedures. As a result, the authors point out, AI often discriminates against women, as well as racial or ethnic groups. Another threat relates to the biased attribution of lower grades or crimes to minorities. The lack of transparency or 'opaqueness' of AI algorithms brings concerns about potential ways to fix the bias.

Prepared using sagej.cls 
Most of today's cutting-edge AI systems are, for example, prone to discriminate against vulnerable groups and minorities. This has led to text analysis software labelling being Jewish or being gay as negative, British students from poor areas being disadvantaged during exams, or a Black American being arrested for a crime he did not commit. (POLITICO Europe, 2020-09-06)

Kitting out our streets, supermarkets, and parks with these technologies will amplify existing discrimination against people of colour, people with disabilities, and other marginalised groups. Instead of being contestable, these practices will be hidden under a veil of false scientific authority and deliberate opacity. (Euronews English, 2021-02-17)

Therefore, the authors claim that any type of AI application in public policies or public space should be preceded by open democratic debate and the technological solutions should be more transparent.

\section{Discussion}

Our study is based on a two-step analysis of the corpus of articles in EU-focused online press. By comparing the results of the quantitative topic analysis with in-depth discourse analysis we managed to confirm the general topics emerging in the studied publications. The qualitative analysis allowed us to distinguish an important sub-topic concerning the pandemic as a fast-tracking factor in technological development and analyze technological threats mentioned in the studied narratives. However, in terms of identifying main topics and trends in the narratives, the quantitative approach seems accurate enough and allows for reviewing large archives of texts in a much shorter time.

Our main takeaway from both analyses is that in the context of momentous technological changes that are underway in Europe, the narrative of the online journals remains rather predictable and shallow, repeating and recycling topics without trying to present deeper arguments and long-term solutions. This is in line with the findings of Zuboff (2019) or Vanolo (2014) who point out how the smart city discourse may be a powerful tool for the production of 'docile subjects' and political legitimization of Big Tech business goals.

What seems to be at stake in terms of the technological race we are witnessing, is that without having an open and inclusive public conversation about smart city development and surveillance implementations, we risk losing the democratic legitimacy of these transformations. As one of the few articles points out:

The evolution of government surveillance is bold, multi-faceted, and confusing. Agencies across the continent are deploying an avalanche of new technologies, notably machine learning, to both advance new capabilities such as biometric surveillance and master long-standing challenges like information overload. (EUobserver, 2019-10-23)

Prepared using sagej.cls 
That is why it is even more crucial for the European journals to focus on something more than Chinese 'horror stories' or naive belief that the GDPR or other EU regulation will be a quick fix to privacy concerns, raise of the surveillance state or lack of democratic control over implemented algorithms. Few of the articles point out how the public turns a blind eye to the fact that Europe became a testing ground for many doubtful technologies, confirming Zuboff (2019) warnings:

Discussions on the negative impact of Artificial Intelligence in society include horror stories plucked from either China's high-tech surveillance state and its use of the controversial social credit system, or from the US and its use of recidivism algorithms and predictive policing. Typically, Europe is excluded from these stories, due to the perception that EU citizens are protected from such AI-fuelled nightmares through the legal protection offered by the GDPR, or because there is simply no horror-inducing AI deployed across the continent. In contrast to this perception, journalists and NGOs have shown that imperfect and ethically questionable AI systems such as facial recognition, fraud detection and smart (a.k.a surveillance) cities, are also in use across Europe. (EURACTIV, 2020-01-22)

When citing EC officials, the articles repeat the promise of good regulations enabling beneficial technologies, while curbing their negative consequences. In the context of the COVID-19 pandemic, however, those regulations were not in place yet, while there was an urgent push to introduce technological measures that could help slow down the virus' spread.

The optimistic narrative about the EU's growing position in 'the global fight for tech supremacy' is based on references to new regulation proposals and policy initiatives. What connects those arguments is the repeated metaphor of the 'digital race' in which the EU must up its game to avoid marginalization or even takeover by global tech players.

The flurry of policy initiatives aims to wean Europe off its dependence on foreign-owned tech companies while bolstering the bloc's own tech sector, with the aim of becoming more competitive against rivals in China and the United States. (POLITICO Europe, 2020-02-19)

Digitalisation is a race we are bound to lose if we do not move quickly. (...) our living standards and the prosperity and security of the entire continent depend on it. However, we are held back by bureaucracy and slow decision-making processes, while our competitors are rushing forward and do not play by the rules. (The Parliament Magazine, 2020-08-04)

This shows that the mainline of arguments is centered around economical interest rather than citizens' rights and concerns. This could be interpreted as a sign that the logic of surveillance capitalism is deeply embedded in the 
European narratives concerning smart technologies. The trade-off between data privacy and economic gains seems to have only one preferred solution - investing in digitalization to ensure 'the digital dividend' to the citizens of Europe.

(...) the largely theoretical gains for data privacy may come at the cost of very real economic pain. Europe is deeply trade-dependent. With more and more trade moving to the digital realm, Europe can ill-afford to cut itself off. Meanwhile, China continues to advance a vision for an internet that is fractured along national boundaries and controlled by governments. (EUobserver, 2020-08-10)

There is a digital dividend waiting for the citizens of Europe if we invest in digitalisation. (The Parliament Magazine, 2021-03-29)

Apart from the economical argument, there are two strong explanations why the only way for digital Europe is forward. One is the aftermath of the pandemic, which means that the region will face even more challenges in terms of public spending on health. This creates an opening for a wider introduction of Artificial Intelligence algorithms and smart solutions (sensors, monitoring devices, remote tracing) in healthcare. As one of the articles from March 2021 points out, the pandemic is a chance to speed up the technological revolution in healthcare:

The question now is whether this pandemic is the moment to make the cultural shift in healthcare needed to take advantage of the technological revolution that digitisation and digitalisation can offer. (Euronews English, 2021-03-30)

Another strong argument enabling digital transformation and the introduction of new smart city technologies is the need for 'twin transition' based on 'digitalization for the benefit of the environment'. An investment program that links environmental aspects with climate neutrality is therefore the logical next step. As another recent analysis points out, this means heavily investing in all previously criticized technologies to meet EU climate goals:

This is the only way we can meet our European environmental and climate goals, enable inclusive, socially just and sustainable economic growth and ensure an increase in competitiveness and prosperity. (EURACTIV, 2021-09-02)

However, our analysis shows that the growing number of positive narratives underling the importance of technology in fighting the pandemic and mitigating climate emergency boils down to the European place in the digital economy race. Therefore, the crucial argument for fast-tracking the smart solutions relates to the need for securing the competitiveness of the EU in the global technological rivalry rather than increasing citizens' wellbeing or safeguarding the democratic transparency of the introduced innovations. This exemplifies Melgaço and Brakel's (2021) concept of smart cities as surveillance theatre in which power relations play an important role.

Prepared using sagej.cls 
Such an approach to digitalization goes against the growing body of critical writing concerning smart cities (Swyngedouw 2016; Cardullo and Kitchin 2019), the roles of private and public entities in bringing innovation to the urban realm (Buck and While 2017), and citizens' rights in the digital society (Shaw and Graham 2017; Foth et al. 2015). As Dean (2017) points out, improving the city for everyone begins with ensuring technology enhances democracy, and smart city solutions and policies focus on the citizens' right to mobilize technology to respond to needs, shape urban spaces, and otherwise benefit from urban data.

However, as Cardullo and Kitchin (2019) point out and our analysis confirms, most attempts to recast the smart city as citizen-focused remain rooted in economic discourses and paternalistic practices rather than those of social rights, political citizenship, and the common good. Moreover, sometimes smart city transitions result only in the creation of the narrative of possible vaguely defined future benefits of implemented digital solutions instead of promised quick fixes to the existing issues (Jirón et al. 2021; Valdez et al. 2018). Despite the need for reflection on digital transformation, the matter is often marginalized even in political discourse. Digitalization is rarely a subject of political debate unless it fits parties' programmatic profile or government finds it to be opportune (König and Wenzelburger 2019). Without new narratives focusing on those values, we cannot hope for better smart city policies, as they require an alternative concept of smart citizenship, guided by the right to the city, not the market logic.

\section{References}

Albino V, Berardi U and Dangelico RM (2013) Smart cities-definitions, dimensions, and performance. Proceedings IFKAD : 1723-1738.

Bevir M and Rhodes R (2006) Governance stories. Routledge.

Blei DM, Ng AY and Jordan MI (2003) Latent dirichlet allocation. Journal of Machine Learning Research 3: 993-1022.

Boin A, Stern E and Sundelius B (2016) The politics of crisis management: Public leadership under pressure. Cambridge University Press.

Buck NT and While A (2017) Competitive urbanism and the limits to smart city innovation: The uk future cities initiative. Urban Studies 54(2): 501-519. DOI: $10.1177 / 0042098015597162$.

Cadwalladr C and Graham-Harrison E (2018) Revealed: 50 million Facebook profiles harvested for Cambridge Analytica in major data breach. URL https://www.theguardian.com/news/2018/mar/17/ cambridge-analytica-facebook-influence-us-election.

Cardullo P and Kitchin R (2019) Smart urbanism and smart citizenship: The neoliberal logic of 'citizen-focused'smart cities in Europe. Environment and planning C: politics and space $37(5)$ : 813-830.

Cohen B (2015) The 3 Generations of Smart Cities. URL https: //www. fastcompany . com/3047795/the-3-generations-of-smart-cities.

Collier P (2016) The cultural foundations of economic failure: A conceptual toolkit. Journal of Economic Behavior \& Organization 126: 5-24.

Prepared using sagej.cls 
Costa DG and Peixoto JPJ (2020) Covid-19 pandemic: a review of smart cities initiatives to face new outbreaks. IET Smart Cities 2(2): 64-73.

Dean M (2017) A Digital Right to the City: who defines democracy in smart cities? URL https://www . bangthetable.com/blog/digital-right-to-the-city/.

Drennan LT, McConnell A and Stark A (2014) Risk and crisis management in the public sector. Routledge.

European Commission (2019) Communication from the Commission to the European Parliament, the European Council, the Council, the European Economic and Social Committee and the Committee of the Regions- The European Green Deal. URL https://eur-lex.europa.eu/legal-content/en/txt/?qid= $1576150542719 \&$ uri $=$ com\%3a2019\%3a640\%3afin.

European Commission (2020a) Communication from the Commission EUROPE 2020: A strategy for smart, sustainable and inclusive growth. URL https://ec . europa.eu/eu2020/pdf/complet $\% 20$ en $\% 20$ barroso $\% 20 \% 20 \% 20007 \%$ $20-\% 20$ europe $\% 202020 \% 20-\% 20$ iighien $\% 20$ version.pdf.

European Commission (2020b) Coronavirus: A common approach for safe and efficient mobile tracing apps across the EU. URL https://ec.europa.eu/commission/ presscorner/detail/en/qanda_20_869.

Foth M, Brynskov M and Ojala T (eds.) (2015) Citizen's right to the digital city. Springer.

Honnibal M, Montani I, Van Landeghem S and Adraine B (2018) spaCy: Industrialstrength Natural Language Processing in Python. URL https://doi.org/10. 5281/zenodo. 5648257.

Hutto C and Gilbert E (2014) Vader: A parsimonious rule-based model for sentiment analysis of social media text. In: Proceedings of the International AAAI Conference on Web and Social Media, volume 8.

Jirón P, Imilán WA, Lange C and Mansilla P (2021) Placebo urban interventions: Observing smart city narratives in Santiago de Chile. Urban Studies 58(3): 601620. DOI:10.1177/0042098020943426.

Jones M, Shanahan E and McBeth M (2014) The science of stories: Applications of the narrative policy framework in public policy analysis. Palgrave Macmillan.

Kitchin R, Coletta C, Evans L and Heaphy L (2018) Creating smart cities. In: Creating smart cities. Routledge, pp. 1-18.

König PD and Wenzelburger G (2019) Why parties take up digitization in their manifestos: An empirical analysis of eight Western European economies. Journal of European Public Policy 26(11): 1678-1695.

Kunzmann KR (2020) Smart Cities After Covid-19: Ten Narratives. disP - The Planning Review 56(2): 20-31.

Löfgren K and Webster CWR (2020) The value of Big Data in government: The case of 'smart cities'. Big Data \& Society 7(1): 1-14.

Melgaço L and van Brakel R (2021) Smart cities as surveillance theatre. Surveillance E Society 19(2): 244-249.

Mimno D, Wallach H, Talley E, Leenders M and McCallum A (2011) Optimizing semantic coherence in topic models. In: Proceedings of the 2011 conference on

Prepared using sagej.cls 
empirical methods in natural language processing. pp. 262-272.

Narlikar A and Sottilotta CE (2021) Pandemic narratives and policy responses: west European governments and COVID-19. Journal of European Public Policy 28(8): $1238-1257$.

Norris P (2001) Digital divide: Civic engagement, information poverty, and the Internet worldwide. Cambridge university press.

Rehurek R and Sojka P (2010) Software framework for topic modelling with large corpora. In: Proceedings of the LREC 2010 workshop on new challenges for NLP frameworks. Citeseer.

Röder M, Both A and Hinneburg A (2015) Exploring the space of topic coherence measures. In: Proceedings of the eighth ACM international conference on Web search and data mining. pp. 399-408.

Shaw J and Graham M (eds.) (2017) Our digital rights to the city. Meatspace Press.

Swyngedouw E (2016) The mirage of the sustainable 'smart city': Planetary urbanization and the spectre of combined and uneven apocalypse. In: Cities in the 21st century. Routledge, pp. 164-176.

Swyngedouw E, Moulaert F and Rodriguez A (2002) Neoliberal urbanization in europe: large-scale urban development projects and the new urban policy. Antipode 34(3): $542-577$.

't Hart P and Tindall K (2009) Framing the global economic downturn: Crisis rhetoric and the politics of recessions. ANU Press.

Valdez AM, Cook M and Potter S (2018) Roadmaps to utopia: Tales of the smart city. Urban Studies 55(15): 3385-3403. DOI:10.1177/0042098017747857.

Vanolo A (2014) Smartmentality: The smart city as disciplinary strategy. Urban studies 51(5): 883-898.

Wood DM (2015) Smart City, Surveillance City. URL https://www.scl.org/ articles/3405-smart-city-surveillance-city.

Wydick B (2015) Impact as narrative. URL https://blogs.worldbank.org/ impactevaluations/impact-narrative-guest-post-bruce-wydick.

Zuboff S (2019) The age of surveillance capitalism: The Fight for a Human Future at the New Frontier of Power. Profile books.

Prepared using sagej.cls 